\title{
The Relationship Between Ultraviolet Light Exposure and Mortality in Dialysis Patients
}

\author{
Bryan B. Shapiro $^{a}$ Elani Streja ${ }^{a, b} \quad$ Joline L.T. Chen ${ }^{a, b}$ Csaba P. Kovesdy ${ }^{c, d}$ \\ Kamyar Kalantar-Zadeha, b, e Connie M. Rhee ${ }^{a, b}$ \\ ${ }^{a}$ Harold Simmons Center for Chronic Disease Research and Epidemiology, Division of Nephrology and \\ Hypertension, University of California Irvine Medical Center, Orange, Calif., bVeterans Affairs Long Beach Health \\ Care System, Long Beach, Calif., ' Memphis Veterans Affairs Medical Center, d University of Tennessee Health Science \\ Center, Memphis, Tenn., and ' $D$ epartments of Environmental Health Sciences and Epidemiology, UCLA Fielding \\ School of Public Health, Los Angeles, Calif., USA
}

\section{Key Words}

Dialysis · Environment · Mortality · Ultraviolet radiation .

Vitamin D

\begin{abstract}
Background: Emerging data suggest that reduced exposure to ultraviolet (UV) radiation is associated with increased mortality in the general population. To date, the association between UV exposure and mortality in dialysis patients has not been examined. Methods: We examined the association between UV index, a proxy of UV exposure, and all-cause mortality among 47,286 US dialysis patients (entry period 20012006, with follow-up through 2009) from a large national dialysis organization using multivariable Cox regression. The UV index was ascertained by linking individual patients' residential zip codes to National Oceanic and Atmospheric Administration data, and was categorized as low $(0-<3)$, moderate $(3-<5)$, moderate-high $(5-<6)$, high $(6-<7)$, and veryhigh $(\geq 7)$. In secondary analyses, we examined the UV index-mortality association within subgroups of age ( $<65$ vs. $\geq 65$ years old), sex, and race (white vs. non-white). Results: The study population's mean \pm SD age was $60 \pm 16$ and included $46 \%$ women and $56 \%$ diabetics. Compared to pa-
\end{abstract}

tients residing in moderate-high UV index regions, those residing in high and very-high UV index regions had a lower mortality risk: adjusted HRs $0.84(95 \% \mathrm{Cl}) 0.81-0.88$ and 0.83 $(95 \% \mathrm{Cl}) 0.75-0.91$, respectively. A similar inverse association between UV index and mortality was observed across all subgroups, although there was more pronounced reduction in mortality among whites vs. non-whites. Conclusion: These data suggest that dialysis patients residing in higher UV index regions have lower all-cause mortality compared to those living in moderate-high UV regions. Further studies are needed to determine the mechanisms underlying the UV index-mortality association.

(c) 2014 S. Karger AG, Basel

\section{Introduction}

There has been increasing interest in the impact of environmental exposures such as ultraviolet (UV) radiation exposure on human health. UV radiation has been classified as a human carcinogen by the US Department of Health and Human Services and the World Health Organization given its causal associations with skin cancer [1]. However, emerging data from the general population

\section{KARGER}

E-Mail karger@karger.com

www.karger.com/ajn
(C) 2014 S. Karger AG, Basel

0250-8095/14/0403-0224\$39.50/0
Connie M. Rhee

Harold Simmons Center for Chronic Disease Research and Epidemiology, Division of Nephrology and Hypertension, University of California Irvine Medical Center, 101 The City Drive South, City Tower, Suite 400 - ZOT: 4088, Orange, CA 92868-3217 (USA) E-Mail crhee1@uci.edu 
suggest that increased UV exposure is associated with decreased risk of certain non-dermatologic malignancies (e.g., prostate, breast, non-Hodgkin's lymphoma) as well as reduced cardiovascular and all-cause mortality [2-4]. It has been hypothesized that increased endogenous synthesis of vitamin D stimulated by UV exposure may be a mechanistic link for this paradoxical association. Indeed, UV irradiance is an important determinant of vitamin D biosynthesis and status in the general population $[5,6]$.

Vitamin D deficiency is highly prevalent in chronic kidney disease (CKD) patients including those who are dialysis-dependent [7-9], and it is associated with increased risk of adverse cardiovascular surrogates, e.g., coronary artery calcification [10], atherosclerosis [11], endothelial dysfunction [11], cardiovascular events [12], and mortality $[13,14]$. Emerging data suggest that, despite impaired conversion of inactivated to activated vitamin $\mathrm{D}$ in dialysis patients, both solar UV exposure [1518] and artificial UV exposure [19] may be important predictors of vitamin D status in this population. Notwithstanding the known impact of vitamin $\mathrm{D}$ on hard outcomes in dialysis patients, the association between UV exposure and mortality risk in this context has not yet been examined.

We hypothesized that dialysis patients residing in areas of high UV exposure have decreased mortality risk compared to those living in areas of lower UV exposure. To better inform the field, we sought to examine the association between UV exposure and all-cause mortality within a large, contemporary cohort of US dialysis patients with comprehensive capture of sociodemographic, comorbidity, and laboratory data.

\section{Materials and Methods}

\section{Study Population}

We examined administrative data from all end-stage renal disease patients who underwent hemodialysis or peritoneal dialysis in one of the DaVita Healthcare Partners Inc. outpatient dialysis facilities during an entry period of July 1, 2001 to June 30, 2006, with follow-up through June 30, 2009. The creation of this cohort has been previously described [20]. The study was approved by the Institutional Review Committees of the Los Angeles Biomedical Research Institute at Harbor-UCLA and DaVita Clinical Research. The requirement for a written consent form was waived because of the large sample size, anonymity of the patients studied, and the nonintrusive nature of the research.

The first (baseline) study quarter was the calendar quarter in which each patient's dialysis vintage was $>45$ days during at least half of that quarter. Patients were included provided that they were $\geq 18$ years old during the baseline quarter, and had available residential zip code and UV exposure data.

Ultraviolet Exposure and Mortality
Ultraviolet Exposure Ascertainment

We sought to examine the association between forecasted ambient UV radiation, quantified by the UV index, and mortality. The UV index was first proposed by Environment Canada and subsequently adopted and standardized by the World Health Organization and the World Meteorological Organization in 1994. It is used to predict the UV radiation intensity reaching the earth's surface, and has been used as a proxy of UV exposure in prior epidemiologic studies [21-23]. The calculation of UV index takes into account stratospheric ozone concentration, cloud coverage, altitude, sun's position, surface albedo, tropospheric aerosol loading [24], and it is additionally adjusted for the variations in skin sensitivity to different wavelengths of light, based on the McKinlay-Diffey erythema action spectrum [25]. The resulting value is scaled by a numerical factor and rounded to the nearest whole number, ranging from zero to the mid-teens. A higher UV index corresponds to more intense UV radiation incident at the surface of a particular location [26].

The National Oceanic and Atmospheric Administration (NOAA) National Weather Center provides daily UV index forecasts for 58 major US cities. Each US state is represented by at least one of these 58 cities, with additional representation in California, Florida, New York, Pennsylvania, and Texas. UV data for each city was applied to all zip codes within the cities' county boundaries, for an aggregate of 5,425 zip codes. UV index values were linked to each individual DaVita dialysis patient using their residential zip codes, ascertained at baseline and updated quarterly. While UV index may be forecasted for any time of the day or year, in this study, each patient's UV index represents the average of the annual noon-time UV index values estimated over his/her respective follow-up period. In primary analyses, UV indices were stratified into five groups, adapted from the Environmental Protection Agency's UV index categories: low $(0-<3)$, moderate $(3-<5)$, moderate-high $(5-<6)$, high $(6-<7)$, and very-high $(\geq 7)$.

\section{Outcome Ascertainment}

The primary outcome of interest was all-cause mortality and this was ascertained from the DaVita database and through the United States Renal Data System database linkage. Patients were followed for the outcome of interest until death, or censoring for kidney transplantation or at the end of the study period (June 30, 2009).

\section{Dialysis Treatment and Laboratory Covariates}

Dialysis vintage was defined as the duration of time between the first day of dialysis treatment and the first day that the patient entered the cohort. To minimize the measurement variability and to address the effect of short-term variation in dietary and fluid intake on weight and laboratory measurements, we averaged all repeated measures for each patient during any given calendar quarter (i.e., over 13 consecutive weeks or 3 months). Blood samples were drawn using uniform techniques in all dialysis clinics and were transported to the DaVita Laboratory in Deland, Florida typically within $24 \mathrm{~h}$, and were measured by automated and standardized methods. Most laboratory values were measured monthly, and serum ferritin and intact parathyroid hormone (PTH) levels were measured at least quarterly. Hemoglobin was measured weekly to bi-weekly in most patients. Most blood samples were collected prior to dialysis with the exception of the post-dialysis serum urea nitrogen. 


\section{Statistical Methods}

Baseline characteristics between UV index categories were compared using non-parametric tests for linear trend. The associations between UV index and mortality were evaluated using Cox proportional hazards regression models. For each analysis, three models were examined with incremental multivariable adjustment for baseline covariates:

(a) Model 1 included the entry calendar quarter;

(b) Model 2 included covariates from Model 1, as well as age, sex, dialysis modality, race/ethnicity (African-Americans, nonHispanic Caucasians, Hispanics, Asians, and other), diabetes mellitus, dialysis vintage, primary insurance, marital status, and dialysis dose (i.e., single-pool Kt/V);

(c) Model 3 included covariates from Model 2, as well as body mass index, baseline comorbidities (alcohol dependence, active smoking, cardiac failure, chronic-obstructive pulmonary disorder, cerebrovascular disease, and peripheral vascular disease), and the following laboratory covariates: serum albumin, calcium, bicarbonate, creatinine, ferritin, hemoglobin, lymphocyte percentage, normalized protein catabolic rate, phosphorus, white blood cell count, alkaline phosphatase, and PTH.

UV index-mortality associations were examined within subgroups of age ( $<65$ years vs. $\geq 65$ years), sex, and race (white vs. non-white). We employed a complete case analysis approach in which analyses were restricted to patients with available data for all covariates used in each respective model, although missing data was $<1 \%$ for most laboratory and demographic variables. All $\mathrm{p}$ values were 2 -tailed $(\mathrm{p}<0.05)$. Analyses were conducted using Stata version 10.1 (Stata Corporation, College Station, Tex., USA).

\section{Results}

\section{Baseline Characteristics}

After excluding patients who were $<18$ years old or who had missing age data; those who did not maintain $\geq 45$ days of thrice-weekly dialysis treatment during the baseline calendar quarter; and those with missing zip code-linked UV index data, the final source cohort consisted of 47,286 dialysis patients. Online supplementary figure 1 (for all online suppl. material, see www.karger. com/doi/10.1159/000367903) shows the distribution of dialysis patients according to their respective UV index categories, with the majority of patients residing in areas of moderate-to-high UV regions.

Baseline demographic, clinical and laboratory data of dialysis patients across the five UV index categories were examined (table 1). Compared to patients residing in the lowest UV index category, those residing in the highest category were more likely to be African-American, Hispanic, divorced, treated with hemodialysis, and of shorter dialysis vintage; had a higher prevalence of diabetes, atherosclerotic heart disease, cardiac failure, and peripheral vascular disease; and had a higher mean residual renal function, ferritin, and PTH levels.

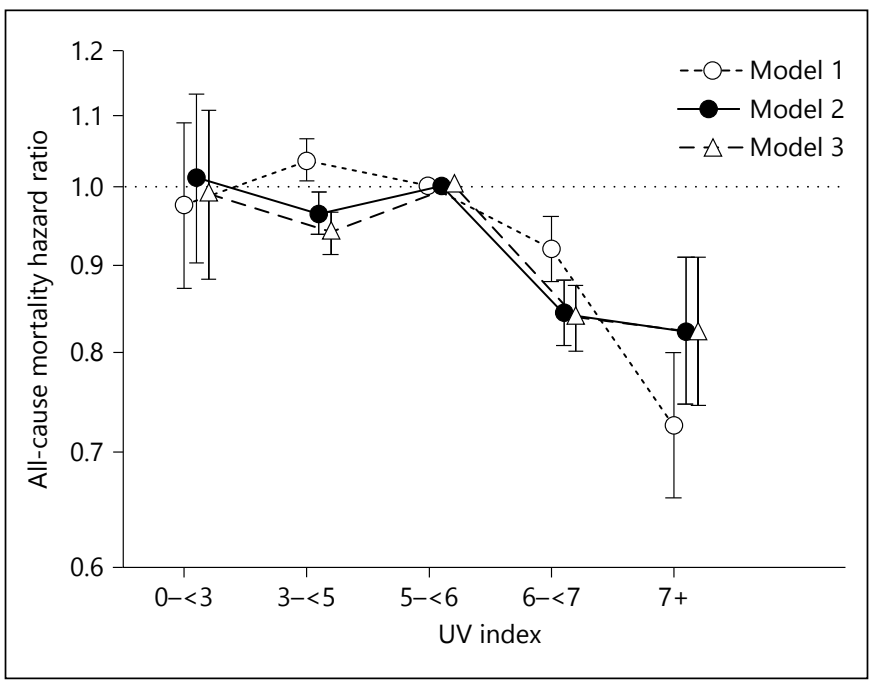

Fig. 1. Association between residential ultraviolet (UV) index divided into five categories (low: $<3$; moderate: $3-<5$; moderate-high: $5-<6$; high: $6-<7$; and very-high: $\geq 7)$ with all-cause mortality in dialysis patients (reference group: UV index 5-<6). Model 1 included UV index category and entry calendar quarter. Model 2 included covariates from Model 1, as well as age, sex, dialysis modality, race/ethnicity, diabetes mellitus, dialysis vintage, primary insurance, marital status, and dialysis dose (i.e., single pool Kt/V). Model 3 included covariates from the Model 2, baseline comorbidities (alcohol dependence, active smoking, cardiac failure, chronic-obstructive pulmonary disorder, cerebrovascular disease, and peripheral vascular disease), body mass index, serum albumin, calcium, bicarbonate, creatinine, ferritin, hemoglobin, lymphocyte percentage, normalized protein catabolic rate, phosphorus, white blood cell count, alkaline phosphatase, and parathyroid hormone.

\section{Ultraviolet Index and Mortality in Dialysis Patients}

The association between residential UV index divided into five categories and all-cause mortality was examined in three Cox regression models with incremental levels of multivariable adjustment (fig. 1 and table 2). Compared to patients living in moderate-to-high UV index areas, those living in high to very-high UV index areas had decreased mortality risk, whereas patients residing in moderate and low UV index areas had decreased and similar mortality risk, respectively.

\section{Subgroup Analyses}

The UV index-mortality association was examined in patients stratified by age ( $<65$ vs. $\geq 65$ years old), sex, and race (white vs. non-white). A similar inverse association between UV index and mortality was observed in all subgroups, although there appeared to be a more pronounced reduction in mortality among whites compared to nonwhites (fig. 2 and online suppl. table 1). 
Table 1. Baseline characteristics among dialysis patients stratified by residential ultraviolet (UV) index category

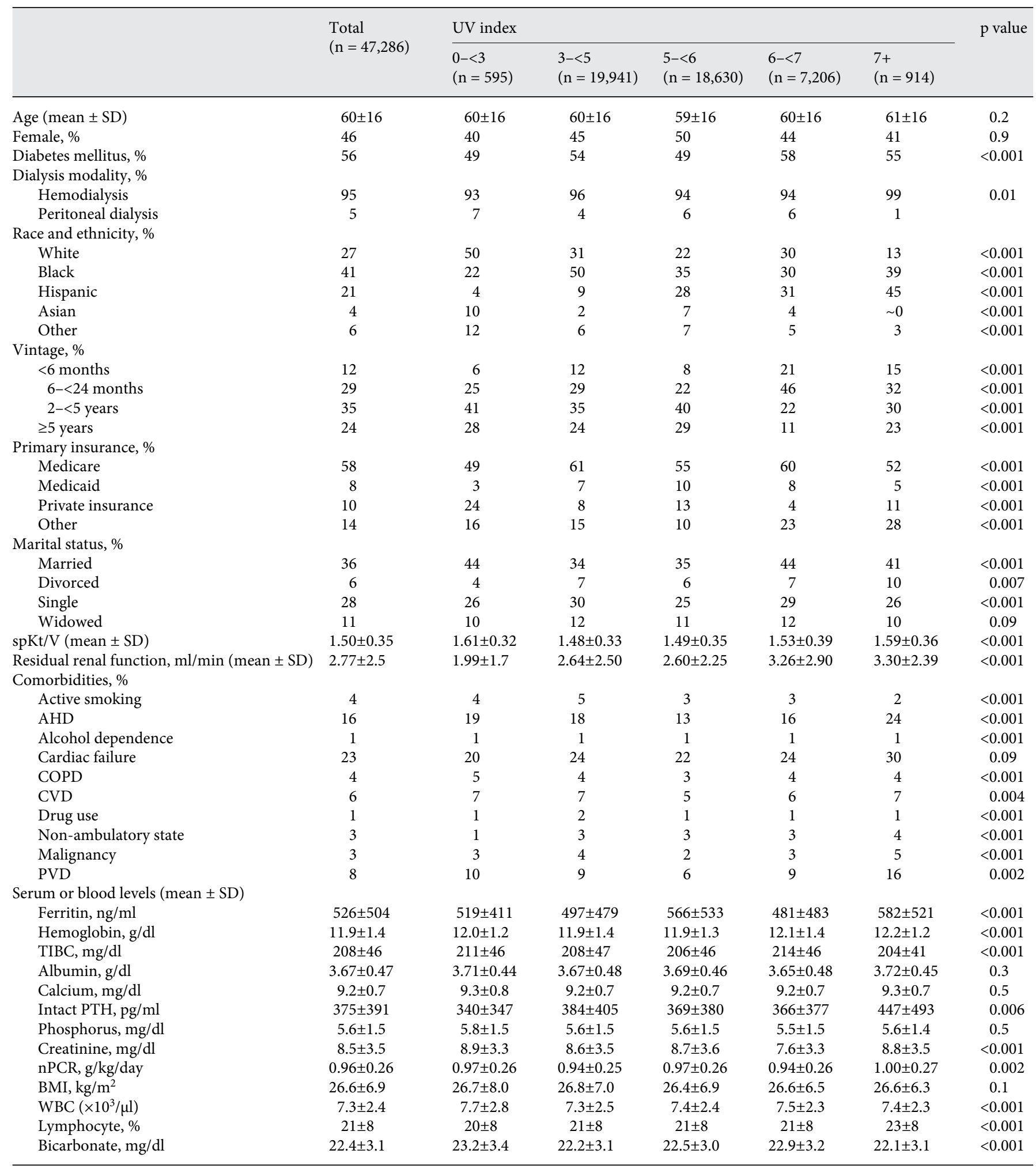

* $\mathrm{p}$ values were calculated using non-parametric tests of linear trend. $\mathrm{SD}=$ Standard deviation; $\mathrm{AHD}=$ atherosclerotic disease; $\mathrm{COPD}=$ chronic-obstructive pulmonary disorder; $\mathrm{CVD}=$ cerebrovascular disease; $\mathrm{PVD}=$ peripheral vascular disease; TIBC = total iron binding capacity; $\mathrm{PTH}=$ parathyroid hormone; $\mathrm{nPCR}=$ normalized protein catabolic rate; $\mathrm{BMI}=$ body mass index; $\mathrm{WBC}=$ white blood cell count. 
Table 2. All-cause mortality hazard ratios (95\% confidence intervals) in dialysis patients across ultraviolet (UV) index categories

\begin{tabular}{lclll}
\hline UV index & $(\mathrm{n}=47,286)$ & $\begin{array}{l}\text { Model } 1^{*} \\
\text { HR }(95 \% \mathrm{CI})\end{array}$ & $\begin{array}{l}\text { Model } 2^{\dagger} \\
\text { HR }(95 \% \mathrm{CI})\end{array}$ & $\begin{array}{l}\text { Model } 3^{\dagger \dagger} \\
\text { HR }(95 \% \mathrm{CI})\end{array}$ \\
\hline $0-<3$ & 595 & $0.98(0.87,1.09)$ & $1.01(0.90,1.13)$ & $0.99(0.88,1.11)$ \\
$3-<5$ & 19,941 & $1.04(1.01,1.07)$ & $0.97(0.94,0.99)$ & $0.94(0.91,0.97)$ \\
$5-<6$ & 18,630 & 1.00 & 1.00 & 1.00 \\
$6-<7$ & 7,206 & $0.92(0.88,0.96)$ & $0.84(0.81,0.88)$ & $0.84(0.80,0.88)$ \\
$7+$ & 914 & $0.73(0.66,0.80)$ & $0.82(0.75,0.91)$ & $0.82(0.74,0.91)$ \\
\hline
\end{tabular}

* Model 1 included UV index category and entry calendar quarter. ${ }^{\dagger}$ Model 2 included covariates from Model 1 , as well as age, sex, dialysis modality, race/ethnicity, diabetes mellitus, dialysis vintage, primary insurance, marital status, and dialysis dose (i.e., single pool Kt/V). ${ }^{\dagger \dagger}$ Model 3 included covariates from Model 2, baseline comorbidities (alcohol dependence, active smoking, cardiac failure, chronic-obstructive pulmonary disorder, cerebrovascular disease, and peripheral vascular disease), body mass index, serum albumin, calcium, bicarbonate, creatinine, ferritin, hemoglobin, lymphocyte percentage, normalized protein catabolic rate, phosphorus, white blood cell count, alkaline phosphatase, and parathyroid hormone.

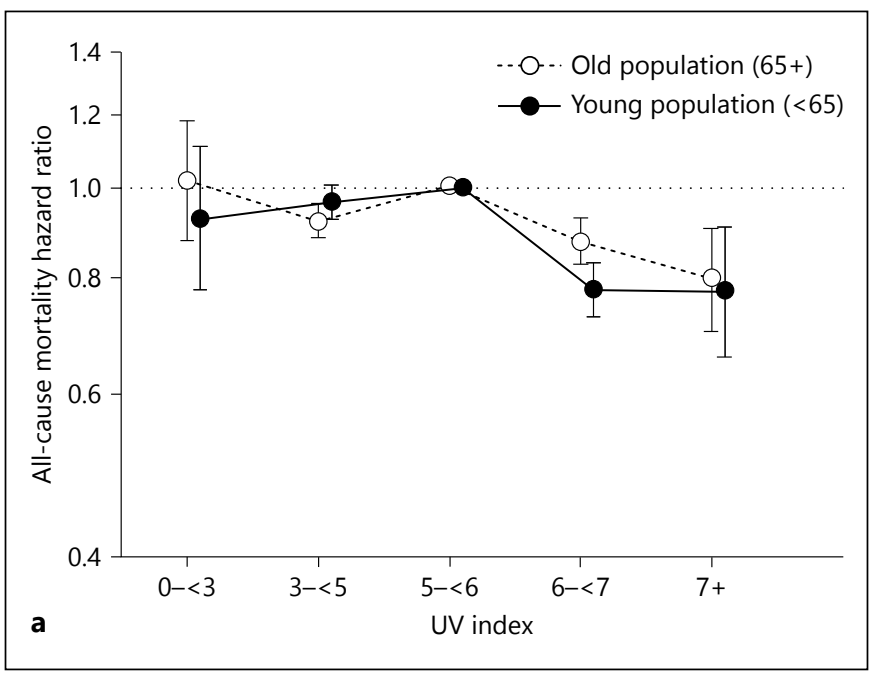

Fig. 2. Association between residential ultraviolet (UV) index divided into five categories (low: $<3$; moderate: $3-<5$; moderatehigh: $5-<6$; high: $6-<7$; and very-high: $\geq 7)$ with all-cause mortality in dialysis patients within subgroups of age ( $<65$ years vs. $\geq 65$ years), sex (female vs. male), and race (white vs. non-white). Models included UV index category, entry calendar quarter, age, sex, dialysis modality, race/ethnicity, diabetes mellitus, dialysis vintage, primary insurance, marital status, dialysis dose (i.e., single pool Kt/V), baseline comorbidities (alcohol dependence, active smoking, cardiac failure, chronic-obstructive pulmonary disorder, cerebrovascular disease, and peripheral vascular disease), body mass index, serum albumin, calcium, bicarbonate, creatinine, ferritin, hemoglobin, lymphocyte percentage, normalized protein catabolic rate, phosphorus, white blood cell count, alkaline phosphatase, and parathyroid hormone.
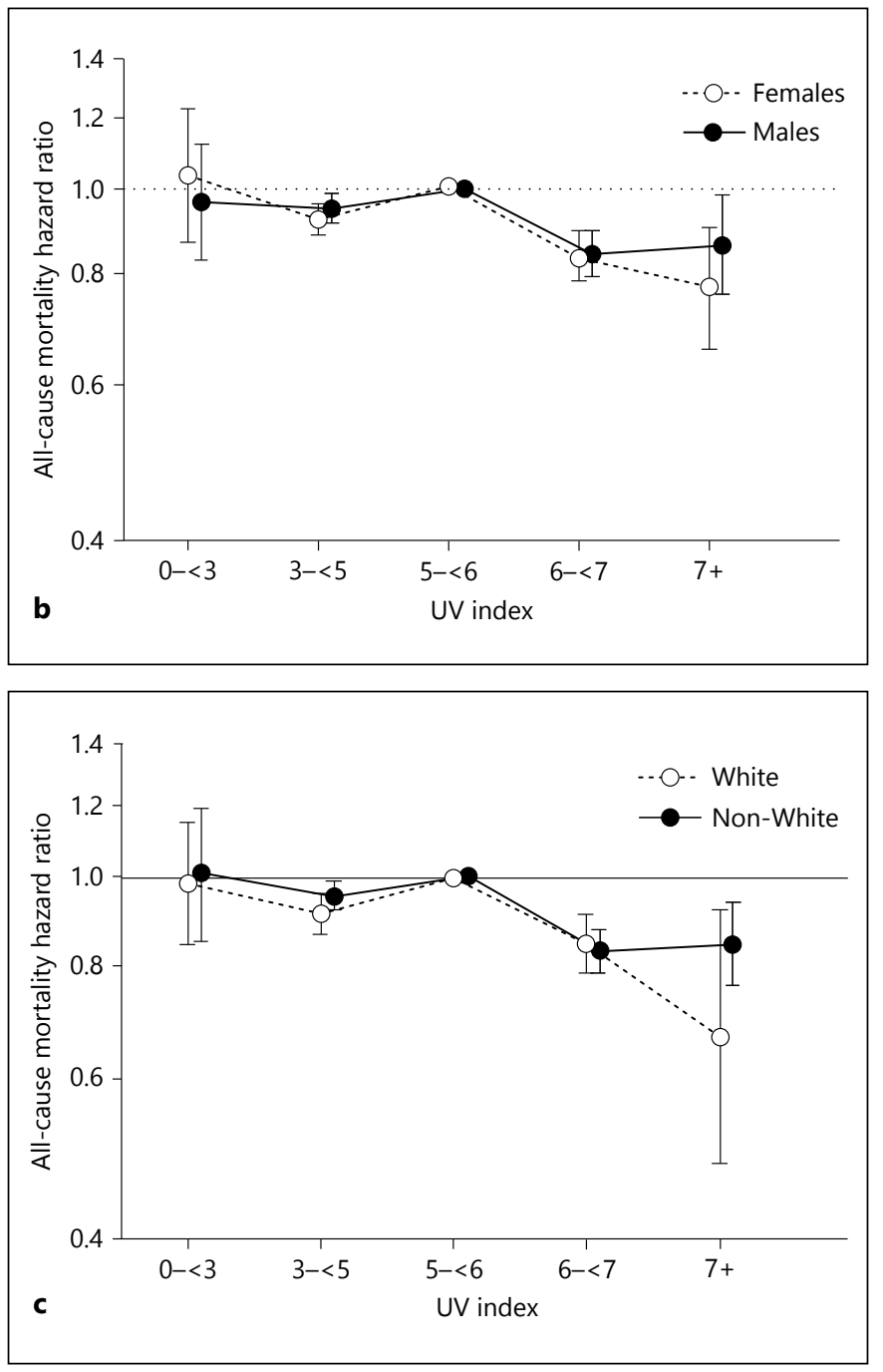


\section{Discussion}

To our knowledge, this is the first study to examine the association between UV exposure and mortality in a contemporary cohort of US dialysis patients. In the general population, there is evidence that solar UV radiation causes skin cancer (e.g., malignant melanoma, basal and squamous cell cancer) via direct induction of DNA damage and indirect effects on immune suppression [27, 28], and it has been deemed to be a carcinogen by the International Agency for Research on Cancer [29]. However, emerging data suggest that UV radiation may also have potential health benefits. A number of ecologic and cohort studies have suggested that there is an inverse association between UV radiation (defined as UV index, solar UV-B radiation, and erythemogenic UV radiation in these studies) with cancer incidence and mortality (renal $[4,30]$, prostate $[3,4,31]$, breast $[4,31,32]$, colon $[4,30-$ $32]$, and rectal $[4,30])$. Furthermore, in a recent prospective cohort study of 38,472 Swedish women, participants who reported higher levels of prior natural and artificial UV exposure (i.e., prior history of sunburn, sunbathing, and solarium use) had decreased all-cause and cardiovascular mortality [2]. In our study, the UV index was employed as an objective metric of forecasted solar radiation, and we observed that individuals living in higher UV exposure regions had decreased mortality risk compared to those living in low-to-moderate UV exposure regions.

Increased biosynthesis of vitamin $\mathrm{D}$ has been suggested as a potential mechanistic link between higher UV indices and decreased cancer incidence and cardiovascular mortality. In terms of the former outcome, vitamin $\mathrm{D}$ has been associated with decreased cancer risk vis-a-vis improved cell differentiation and apoptosis, anti-angiogenesis, decreased metastases, and decreased risk of viral infection-associated malignancies in some [33-35], but not all studies [36]. In terms of the latter outcome, multiple observational studies have reported an inverse association between vitamin $\mathrm{D}$ levels and greater risk of adverse cardiovascular surrogates, cardiovascular events and mortality in populations with [12-14] and without [3739] chronic kidney disease (CKD). Solar UV-B radiation promotes the conversion of 7-dehydrocholesterol to previtamin $\mathrm{D}_{3}$ in skin tissue, which is isomerized to vitamin $\mathrm{D}_{3}$ (i.e., cholecalciferol) by body temperature. Subsequently, vitamin $\mathrm{D}_{3}$ is hydroxylated by cytochrome $\mathrm{p} 450$ enzymes in the liver, forming 25 -hydroxy-vitamin $\mathrm{D}$ (i.e., calcidiol), the major circulating form of vitamin D. Inactive 25-hydroxy-vitamin $\mathrm{D}$ is then converted into active 1,25-dihydroxy-vitamin $\mathrm{D}$ (i.e., calcitriol), by the 1- $\alpha$ hy- droxylase enzyme present in various parts of the nephron [40]. Although 1,25-dihydroxy-vitamin D production is downregulated in advanced CKD as a result of hyperphosphatemia [41], uremia [42, 43], metabolic acidosis [44], and elevated fibroblast growth factor-23 [45, 46], experimental and clinical studies have shown that administration of 25-hydroxy-vitamin D, even in anephric individuals [18], is associated with significant increases in activated vitamin $\mathrm{D}$. This may be due to the presence of 1- $\alpha$ hydroxylase in other tissues (e.g., skin, lymph nodes, gastrointestinal tract, pancreas, heart, and adrenal glands) as an extra-renal source of activated vitamin D $[47,48]$.

Cardiovascular disease is the leading cause of death in $\mathrm{CKD}$, and vitamin D deficiency is associated with an increased risk of cardiovascular risk factors (e.g., albuminuria [49]), adverse cardiovascular surrogates (e.g., coronary artery calcification [10], atherosclerosis [11], endothelial dysfunction [11]) as well as increased risk of cardiovascular events [12] and all-cause mortality in this population $[13,14]$. Observational studies have suggested that treatment with activated vitamin $D$ reduces all-cause and cardiovascular mortality in patients with CKD, including those who are non-dialysis dependent and those receiving dialysis [50-54]. Although several studies suggest 25-hydroxy-vitamin $\mathrm{D}$ treatment may have benefits on cardiovascular surrogates in CKD patients $[55,56]$, there have not been any well-designed, randomized controlled trials or large observational cohort studies examining hard outcomes in this context.

Emerging data suggest that reduced sunlight exposure may be a predictor of vitamin $\mathrm{D}$ deficiency in dialysis patients [17], and that artificial UV radiation may be an alternative source for vitamin $\mathrm{D}$ repletion in this context. In an observational cohort study of 15 dialysis patients, narrow-band UV-B treatment over a 3-week period resulted in a significant increase in serum 25-hydroxy and 1,25-dihydroxy-vitamin D levels [19]. Although dialysis patients may be less likely to participate in outdoor physical activity and hence have reduced natural UV exposure $[57,58]$, even brief durations of solar or artificial UV exposure have been shown to significantly increase vitamin D levels in the general population [59-62]; further study is needed to determine if natural UV radiation may be a viable source of vitamin $\mathrm{D}$ repletion in dialysis patients. Due to data limitations, we were not able to directly ascertain patients' frequency or duration of outdoor activity, other factors that modify UV exposure (e.g., photosensitizing medications or photo-protective clothing), or vitamin D levels in our study; however, it is plausible that 
patients residing in higher UV index regions experience greater solar UV radiation exposure and subsequent synthesis of vitamin D. Future studies directly measuring solar UV radiation exposure, serum vitamin D levels, and cardiovascular outcomes in CKD patients are needed.

When we examined the associations between UV index and mortality across subgroups of race, higher UV index categories were associated with a more potent survival benefit among white patients compared to nonwhites in the highest UV index category $(\geq 7)$. While genetic polymorphisms may partially account for variations in total vitamin D level across racial groups [63], lightskinned individuals experience greater UV-B absorption and subsequent vitamin $\mathrm{D}$ synthesis as a result of their reduced melanin skin content, compared to those who are non-white $[64,65]$.

Strengths of our study include the examination of a large, contemporary US dialysis population with extended follow-up; comprehensive availability of clinical data allowing for adjustment of multiple confounders; examination of individual patients' residential UV indices; and use of a validated assessment of UV exposure that accounts for potential confounders such as altitude. However, several limitations of our study bear mention. First, our analyses examined only the quarterly residential UV index and did not account for patients who may have migrated over time within that period. Second, we are unable to confirm that an individual's residential UV index, which is a forecast, directly correlates with the patient's actual UV exposure. Third, given that the National Oceanic and Atmospheric Administration measures UV index in major US cities only, our study cohort may not be representative of dialysis patients living in outlier or rural regions. Fourth, while we attempted to adjust for broad markers of nutritional status (e.g., normalized protein catabolic rate, serum albumin) in our multivariable models, due to data limitations we were unable to account for more granular nutritional variables (e.g., diet, nutritional supplements) that may confound the UV index-mortality association. For example, there may be regional variation in dietary intake (including foods that are supplemented with vitamin D), or utilization of vitamin D supplements that are also associated with mortality [66]. Lastly, as with all observational studies, we cannot confirm that there is a causal association between UV index and mortality.

Our data suggest that higher UV index is associated with survival benefit, and that these associations may be even more pronounced among dialysis patients vs. the US general population. Further studies are needed to confirm findings, and to determine the mechanistic pathways by which the UV index is associated with mortality risk in dialysis patients.

\section{Acknowledgements}

Portions of these data have been presented in an abstract published in the Journal of the American Society of Nephrology; a poster presentation at the American Society of Nephrology annual conference, October 27-31, 2012, San Diego, CA; and an oral abstract presentation at the Annual Dialysis Conference, March 9-13, 2013, Seattle, WA.

\section{Support}

The authors are supported by research grants from the NIH/ NIDDK including K24-DK091419 (KKZ), K23-DK102903 (CMR), R01-DK078106 (KKZ), and philanthropist grants from Mr. Harold Simmons and Mr. Louis Chang.

\section{Disclosure Statement}

KKZ was medical director of the DaVita Harbor-UCLA Long Beach from 2007-2012. BBS, ES, JLTC, CPK, and CMR have nothing to declare.

\section{References}

1 Young C: Solar ultraviolet radiation and skin cancer. Occup Med (Lond) 2009;59:82-88.

$\checkmark 2$ Yang L, Lof M, Veierod MB, Sandin S, Adami HO, Weiderpass E: Ultraviolet exposure and mortality among women in Sweden. Cancer Epidemiol Biomarkers Prev 2011;20:683-690.

-3 Colli JL, Grant WB: Solar ultraviolet B radiation compared with prostate cancer incidence and mortality rates in United States. Urology 2008;71:531-535.

4 Boscoe FP, Schymura MJ: Solar ultraviolet-B exposure and cancer incidence and mortality in the United States, 1993-2002. BMC Cancer 2006;6:264.

5 Holick MF: McCollum Award Lecture, 1994: vitamin $\mathrm{D}$ - new horizons for the 21st century. Am J Clin Nutr 1994;60:619-630.

6 Holick MF: Vitamin D: importance in the prevention of cancers, type 1 diabetes, heart disease, and osteoporosis. Am J Clin Nutr 2004;79:362-371.

7 Pilz S, Tomaschitz A, Friedl C, Amrein K, Drechsler C, Ritz E, Boehm BO, Grammer TB, Marz W: Vitamin D status and mortality in chronic kidney disease. Nephrol Dial Transplant 2011;26:3603-3609.

8 Bansal B, Bansal S, Mithal A, Kher V, Marwaha R: Vitamin D deficiency in hemodialysis patients. Indian J Endocrinol Metab 2012;16: 270-273.

9 Saab G, Young DO, Gincherman Y, Giles K, Norwood K, Coyne DW: Prevalence of vita$\min \mathrm{D}$ deficiency and the safety and effectiveness of monthly ergocalciferol in hemodialysis patients. Nephron Clin Pract 2007; 105:c132-c138. 
$\checkmark 10$ de Boer IH, Kestenbaum B, Shoben AB, Michos ED, Sarnak MJ, Siscovick DS: 25-hydroxyvitamin D levels inversely associate with risk for developing coronary artery calcification. J Am Soc Nephrol 2009;20:1805-1812.

-11 London GM, Guerin AP, Verbeke FH, Pannier B, Boutouyrie P, Marchais SJ, Metivier F: Mineral metabolism and arterial functions in end-stage renal disease: potential role of 25-hydroxyvitamin D deficiency. J Am Soc Nephrol 2007;18:613-620.

-12 Wang AY, Lam CW, Sanderson JE, Wang M, Chan IH, Lui SF, Sea MM, Woo J: Serum 25-hydroxyvitamin D status and cardiovascular outcomes in chronic peritoneal dialysis patients: a 3-year prospective cohort study. Am J Clin Nutr 2008;87:1631-1638.

-13 Ravani P, Malberti F, Tripepi G, Pecchini P, Cutrupi S, Pizzini P, Mallamaci F, Zoccali C: Vitamin D levels and patient outcome in chronic kidney disease. Kidney Int 2009;75: 88-95.

14 Wolf M, Shah A, Gutierrez O, Ankers E, Monroy M, Tamez H, Steele D, Chang Y, Camargo CA Jr, Tonelli M, Thadhani R: Vitamin D levels and early mortality among incident hemodialysis patients. Kidney Int 2007;72:10041013.

15 Petchey WG, Johnson DW, Hawley CM, Isbel NM: Predictors of vitamin D status in predialysis chronic kidney disease patients: a crosssectional analysis in a high ultraviolet climate. J Ren Nutr 2012;22:400-408.

16 Cuppari L, Carvalho AB, Draibe SA: Vitamin $D$ status of chronic kidney disease patients living in a sunny country. J Ren Nutr 2008; 18 : 408-414.

-17 Del Valle E, Negri AL, Aguirre C, Fradinger E, Zanchetta JR: Prevalence of $25(\mathrm{OH})$ vitamin $\mathrm{D}$ insufficiency and deficiency in chronic kidney disease stage 5 patients on hemodialysis. Hemodial Int 2007;11:315-321.

-18 Sorensen OH, Lund B, Thode JD, Storm TL, Lund B, Brahm M, Friedberg M, Holmegaard SN: Effect of sunlight exposure on circulating 1,25-dihydroxyvitamin $\mathrm{D}$ in hemodialyzed patients and of exogenous parathyroid hormone in anephric patients. Acta Med Scand 1986;219:215-219.

-19 Ala-Houhala MJ, Vahavihu K, Hasan T, Kautiainen H, Snellman E, Karisola P, Dombrowski Y, Schauber J, Saha H, Reunala T: Narrow-band ultraviolet $\mathrm{B}$ exposure increases serum vitamin $D$ levels in haemodialysis patients. Nephrol Dial Transplant 2012;27: 2435-2440.

20 Lukowsky LR, Kheifets L, Arah OA, Nissenson AR, Kalantar-Zadeh K: Patterns and predictors of early mortality in incident hemodialysis patients: new insights. Am J Nephrol 2012;35:548-558.

21 Eide MJ, Weinstock MA: Association of UV index, latitude, and melanoma incidence in nonwhite populations - US Surveillance, Epidemiology, and End Results (SEER) Program, 1992-2001. Arch Dermatol 2005;141:477481.
22 Walls AC, Han J, Li T, Qureshi AA: Host risk factors, ultraviolet index of residence, and incident malignant melanoma in situ among US women and men. Am J Epidemiol 2013;177: 997-1005.

23 Wei-Passanese EX, Han J, Lin W, Li T, Laden F, Qureshi AA: Geographical variation in residence and risk of multiple nonmelanoma skin cancers in US women and men. Photochem Photobiol 2012;88:483-489.

24 Sin C, Beauchet A, Marchal A, Sigal ML, Mahe E: [Understanding and use of the global solar UV index ('UV index') by French dermatologists]. Ann Dermatol Venereol 2013; 140:15-20.

25 McKinlay AF, Diffey BL: A reference action spectrum for ultraviolet induced erythema in human skin. CIE Journal 1987;6:17-22.

26 Kinney JP, Long CS: The Ultraviolet Index: a useful tool. Dermatol Online J 2000;6:2.

27 Marrot L, Meunier JR: Skin DNA photodamage and its biological consequences. J Am Acad Dermatol 2008;58(5 suppl 2):S139S148.

28 Ullrich SE: Sunlight and skin cancer: lessons from the immune system. Mol Carcinog 2007; 46:629-633.

29 Balk SJ: Ultraviolet radiation: a hazard to children and adolescents. Pediatrics 2011; 127:e791-e817.

30 Grant WB, Garland CF: The association of solar ultraviolet B (UVB) with reducing risk of cancer: multifactorial ecologic analysis of geographic variation in age-adjusted cancer mortality rates. Anticancer Res 2006; 26(4A):2687-2699.

- 31 Robsahm TE, Tretli S, Dahlback A, Moan J: Vitamin D3 from sunlight may improve the prognosis of breast-, colon- and prostate cancer (Norway). Cancer Causes Control 2004; 15:149-158.

- 32 Freedman DM, Dosemeci M, McGlynn K: Sunlight and mortality from breast, ovarian, colon, prostate, and non-melanoma skin cancer: a composite death certificate based casecontrol study. Occup Environ Med 2002;59: 257-262.

33 Grant WB: How strong is the evidence that solar ultraviolet $B$ and vitamin $D$ reduce the risk of cancer? An examination using Hill's criteria for causality. Dermatoendocrinol 2009;1:17-24.

34 Majewski S, Skopinska M, Marczak M, Szmurlo A, Bollag W, Jablonska S: Vitamin D3 is a potent inhibitor of tumor cell-induced angiogenesis. J Investig Dermatol Symp Proc 1996;1:97-101.

35 Nakagawa K, Kawaura A, Kato S, Takeda E, Okano T: 1 alpha,25-Dihydroxyvitamin $\mathrm{D}(3)$ is a preventive factor in the metastasis of lung cancer. Carcinogenesis 2005;26:429-440.

36 Lin SW, Wheeler DC, Park Y, Spriggs M, Hollenbeck AR, Freedman DM, Abnet CC: Prospective study of ultraviolet radiation exposure and mortality risk in the United States. Am J Epidemiol 2013;178:521-533.

37 Wang TJ, Pencina MJ, Booth SL, Jacques PF, Ingelsson E, Lanier K, Benjamin EJ, D’Agostino
RB, Wolf M, Vasan RS: Vitamin D deficiency and risk of cardiovascular disease. Circulation 2008;117:503-511.

38 Dobnig H, Pilz S, Scharnagl H, Renner W, Seelhorst U, Wellnitz B, Kinkeldei J, Boehm BO, Weihrauch G, Maerz W: Independent association of low serum 25-hydroxyvitamin D and 1,25-dihydroxyvitamin D levels with allcause and cardiovascular mortality. Arch Intern Med 2008;168:1340-1349.

39 Giovannucci E, Liu Y, Hollis BW, Rimm EB: 25-hydroxyvitamin D and risk of myocardial infarction in men: a prospective study. Arch Intern Med 2008;168:1174-1180.

40 Nigwekar SU, Bhan I, Thadhani R: Ergocalciferol and cholecalciferol in CKD. Am J Kidney Dis 2012;60:139-156.

41 Li YC: Renoprotective effects of vitamin D analogs. Kidney Int 2010;78:134-139.

42 Vanholder R, Patel S, Hsu CH: Effect of uric acid on plasma levels of $1,25(\mathrm{OH}) 2 \mathrm{D}$ in renal failure. J Am Soc Nephrol 1993;4:1035-1038.

43 Hsu CH, Vanholder R, Patel S, De Smet RR, Sandra P, Ringoir SM: Subfractions in uremic plasma ultrafiltrate inhibit calcitriol metabolism. Kidney Int 1991;40:868-873.

44 Kawashima H, Kraut JA, Kurokawa K: Metabolic acidosis suppresses 25-hydroxyvitamin in D3-1alpha-hydroxylase in the rat kidney. Distinct site and mechanism of action. J Clin Invest 1982;70:135-140.

45 Shimada T, Hasegawa H, Yamazaki Y, Muto T, Hino R, Takeuchi Y, Fujita T, Nakahara K, Fukumoto S, Yamashita T: FGF-23 is a potent regulator of vitamin D metabolism and phosphate homeostasis. J Bone Miner Res 2004;19: 429-435.

46 Gutierrez O, Isakova T, Rhee E, Shah A, Holmes J, Collerone G, Juppner H, Wolf M: Fibroblast growth factor-23 mitigates hyperphosphatemia but accentuates calcitriol deficiency in chronic kidney disease. J Am Soc Nephrol 2005;16:2205-2215.

47 Adams JS, Hewison M: Extrarenal expression of the 25-hydroxyvitamin D-1-hydroxylase. Arch Biochem Biophys 2012;523:95-102.

48 Qazi RA, Martin KJ: Vitamin D in kidney disease: pathophysiology and the utility of treatment. Rheum Dis Clin North Am 2012;38: 115-123.

49 de Boer IH, Ioannou GN, Kestenbaum B, Brunzell JD, Weiss NS: 25-Hydroxyvitamin D levels and albuminuria in the Third National Health and Nutrition Examination Survey (NHANES III). Am J Kidney Dis 2007;50:6977.

50 Kalantar-Zadeh K, Kovesdy CP: Clinical outcomes with active versus nutritional vitamin D compounds in chronic kidney disease. Clin J Am Soc Nephrol 2009;4:1529-1539.

51 Kalantar-Zadeh K, Miller JE, Kovesdy CP, Mehrotra R, Lukowsky LR, Streja E, Ricks J, Jing J, Nissenson AR, Greenland S, Norris KC: Impact of race on hyperparathyroidism, mineral disarrays, administered vitamin $\mathrm{D}$ mimetic, and survival in hemodialysis patients. J Bone Miner Res 2010;25:2724-2734. 
52 Kovesdy CP: Survival benefits with vitamin $D$ receptor activation: new insights since 2003. Clin J Am Soc Nephrol 2010;5:17041709.

53 Kovesdy CP, Ahmadzadeh S, Anderson JE, Kalantar-Zadeh K: Association of activated vitamin $\mathrm{D}$ treatment and mortality in chronic kidney disease. Arch Intern Med 2008;168: 397-403.

54 Shinaberger CS, Kopple JD, Kovesdy CP, McAllister CJ, van Wyck D, Greenland S, Kalantar-Zadeh K: Ratio of paricalcitol dosage to serum parathyroid hormone level and survival in maintenance hemodialysis patients. Clin J Am Soc Nephrol 2008;3:17691776.

55 Bucharles S, Barberato SH, Stinghen AE, Gruber B, Piekala L, Dambiski AC, Custodio MR, Pecoits-Filho R: Impact of cholecalciferol treatment on biomarkers of inflammation and myocardial structure in hemodialysis patients without hyperparathyroidism. J Ren Nutr 2012;22:284-291.

-56 Matias PJ, Jorge C, Ferreira C, Borges M, Aires I, Amaral T, Gil C, Cortez J, Ferreira A: Cholecalciferol supplementation in hemodialysis patients: effects on mineral metabolism, inflammation, and cardiac dimension parameters. Clin J Am Soc Nephrol 2010;5:905-911.
57 Johansen KL, Chertow GM, Kutner NG, Dalrymple LS, Grimes BA, Kaysen GA: Low level of self-reported physical activity in ambulatory patients new to dialysis. Kidney Int 2010; 78:1164-1170.

58 Agarwal R, Light RP: Sleep and activity in chronic kidney disease: a longitudinal study. Clin J Am Soc Nephrol 2011;6:1258-1265.

59 Holick MF: Vitamin D deficiency. N Engl J Med 2007;357:266-281.

60 Reid IR, Gallagher DJ, Bosworth J: Prophylaxis against vitamin $\mathrm{D}$ deficiency in the elderly by regular sunlight exposure. Age Ageing 1986;15:35-40.

61 Rhodes LE, Webb AR, Fraser HI, Kift R, Durkin MT, Allan D, O'Brien SJ, Vail A, Berry JL: Recommended summer sunlight exposure levels can produce sufficient $(>$ or $=20 \mathrm{ng}$ $\mathrm{ml}(-1)$ ) but not the proposed optimal $(>$ or $=$ $32 \mathrm{ng} \mathrm{ml}(-1)) 25(\mathrm{OH}) \mathrm{D}$ levels at UK latitudes. J Invest Dermatol 2010;130:1411-1418.

62 Sato Y, Iwamoto J, Kanoko T, Satoh K: Amelioration of osteoporosis and hypovitaminosis $\mathrm{D}$ by sunlight exposure in hospitalized, elderly women with Alzheimer's disease: a randomized controlled trial. J Bone Miner Res 2005;20:1327-1333.
63 Powe CE, Evans MK, Wenger J, Zonderman AB, Berg AH, Nalls M, Tamez H, Zhang D, Bhan I, Karumanchi SA, Powe NR, Thadhani R: Vitamin D-binding protein and vitamin D status of black Americans and white Americans. N Engl J Med 2013;369:1991-2000.

64 Brenner M, Hearing VJ: The protective role of melanin against UV damage in human skin. Photochem Photobiol 2008;84:539-549.

-65 Farrar MD, Kift R, Felton SJ, Berry JL, Durkin MT, Allan D, Vail A, Webb AR, Rhodes LE: Recommended summer sunlight exposure amounts fail to produce sufficient vitamin D status in UK adults of South Asian origin. Am J Clin Nutr 2011;94:1219-1224.

66 Freisling H, Fahey MT, Moskal A, Ocké MC, Ferrari P, Jenab M, Norat T, Naska A, Welch AA, Navarro C, Schulz M, Wirfält E, Casagrande $\mathrm{C}$, Amiano $\mathrm{P}$, Ardanaz E, Parr C, Engeset D, Grioni S, Sera F, Bueno-de-Mesquita B, van der Schouw YT, Touvier M, BoutronRuault MC, Halkjaer J, Dahm CC, Khaw KT, Crowe F, Linseisen J, Kröger J, Huybrechts I, Deharveng G, Manjer J, Agren A, Trichopoulou A, Tsiotas K, Riboli E, Bingham S, Slimani $\mathrm{N}$ : Region-specific nutrient intake patterns exhibit a geographical gradient within and between European countries. J Nutr 2010;140: 1280-1286. 